\title{
MARX E A TEMÁTICA DA EDUCAÇÃO: UM ESTUDO DA CRÍTICA DO PROGRAMA DE GOTHA (1875)
}

\author{
José Salvador de Almeida ${ }^{1}$ \\ Eduardo Ferreira Chagas ${ }^{2}$
}

\begin{abstract}
Resumo:
O presente artigo analisa a temática da educação na obra, a saber, Crítica do Programa de Gotha, escrita por Karl Marx, em 1875, e publicada pela primeira vez, em 1891, por Friedrich Engels, em Die Neue Zeit, n ${ }^{\circ}$ 18, v. 1, 1890-1891. Aqui, neste trabalho, utiliza-se a edição brasileira, traduzida por Rubens Enderle, e publicada pela Boitempo Editorial em 2012. A pesquisa, de natureza qualitativa, de procedimento bibliográfico, pretende apresentar um estudo teórico sobre a proposta de educação defendida por Marx no comentário dirigido ao projeto de programa de unificação dos partidos socialistas operários alemães (Associação Geral dos Trabalhadores Alemães e Partido Social-Democrata dos Trabalhadores). A partir do conjunto de notas, verificouse que Marx não advoga por uma educação que colabora com a lógica do Capital. Marx defende, neste documento, escolas técnicas (teóricas e práticas) combinadas com a escola pública e, na ocasião, condena a defesa de uma educação popular sob a incumbência do Estado, afirmando, ainda, que o governo e a Igreja devem ser excluídos de qualquer influência sobre a escola.
\end{abstract}

Palavras-chave: Marx. Educação. Escola Pública. Capitalismo.

\section{MARX AND THE THEME OF EDUCATION: A STUDY OF THE CRITICISM OF THE GOTHA PROGRAM (1875)}

\begin{abstract}
:
The present article analyses the education's thematic in Marx's work, specifically, throughout his paper Critique of the Gotha Program - written in 1875, and published by the first time in 1891 by his fellow Friedrich Engels in Die Neue Zeit $n^{\circ} 18$ v.1 throughout 1890-1891. It is used, for this matter, the brazilian edition, translated by Rubens Enderle, and published by Boitempo Editorial in 2012. This research attains to a qualitative approach, throughout a bibliographical procedure, intending to present a theoretical study about Marx's education proposition, categorically, Marx's endorsement of education, based on a commentary presented on the book mentioned above, directed to (the german workers in) the Socialists' party unification program (General association of the german workers and the Social-democratic Party). From Marx's notes in this paper it is possible to indicate that his position does not advocate for a concept of education that corroborates by any means with the Capital's inherent logic. It is possible to claim, then, that Marx supports technical education intertwined with public education in general and, on this occasion, condemns any endorsement of a popular education subjugated by the State, asserting also that the government and the church must be prohibited of having any influence on the education itself.
\end{abstract}

Keywords: Marx. Education. Public education. Capitalism.

1 Doutorando em Educação pela Universidade Estadual do Ceará (PPGE/UECE). E - Mail: salvadoralmeida002@gmail.com. http://orcid.org/0000-0002-1036-8381

2 Doutor em Filosofia pela Universidade Alemã de Kassel; Professor de Graduação e Pós-Graduação do Curso de Filosofia da Universidade Federal do Ceará (UFC); Colaborador do Programa de Pós-Graduação da Faculdade de Educação (FACED) da UFC e Colaborador do Programa de Pós-Graduação do Mestrado Acadêmico em Filosofia da Universidade Estadual do Ceará (UECE). Bolsista do CNPQ. E-mail: ef.chagas@uol.com.br. Homepage: http://efchagasufc.wordpress.com. http://orcid.org/0000-0003-1957-6117 


\title{
1-) A contextualização da Crítica do Programa de Gotha (1875) no debate da época
}

De acordo com Michael Löwy, no prefácio à edição brasileira, da Crítica do Programa de Gotha (1875),

\begin{abstract}
O ano de 1875 assistiu à unificação, na cidade de Gotha, dos dois partidos operários alemães: a Associação Geral dos Trabalhadores Alemães (na sigla alemã, ADAV), fundada em 1863, em Leipzig, por Ferdinand Lassalle (que morreu num duelo em 1864), e o Partido Social-Democrata dos Trabalhadores (SDAP), fundado em 1869, em Eisenach, por Wilhelm Liebknecht, Wilhelm Bracke e August Bebel, dirigentes socialistas próximos de Marx. [...]. (MARX, 2012, p. 9).
\end{abstract}

Em torno dessa unificação, encontraremos o famoso escrito de Marx, uma crítica acadêmica e muito barulhenta contra a proposta de programa de unificação dos citados partidos operários que tinham como embasamento teórico as teses de Ferdinand Lassalle.

Na carta ${ }^{3}$ escrita por Marx e enviada a Wilhelm Bracke, um dos membros do Partido-Social Democrata dos Trabalhadores, em 05 de maio de 1875, encontra-se registrado o seguinte posicionamento de Marx: "Depois da realização do congresso de coalizão, Engels e eu publicaremos uma nota curta, esclarecendo que nos distanciamos totalmente desse programa de princípios e não temos nada a ver com ele.” (MARX, 2012, p. 19-20). MarX esclarece o seu posicionamento a respeito do assunto, afirmando que é necessária tal postura, uma vez que, no exterior, "espalha-se a ideia - absolutamente errônea, alimentada com o mais extremo zelo pelos inimigos do partido - de que em segredo dirigimos daqui o movimento do chamado Partido de Eisenach.” (MARX, 2012, p.20). Cita também, que no texto recente, publicado em russo, Bakunin o tornava responsável por todos os programas daquele partido e até por cada passo de Liebknecht e sua cooperação com o Partido Popular.

Segundo Marx, tal programa é absolutamente nefasto e desmoralizador para o partido e não vale nada, "mesmo que não se leve em conta a canonização dos artigos de fé lassallianos." (MARX, 2012, p. 21).

É importante destacar que Marx e Engels não se colocaram contra a unificação dos dois partidos operários alemães ${ }^{4}$, conforme podemos verificar na seguinte passagem:

Recomendamos a leitura da carta de Karl Marx a Wilhelm Bracke, escrita em Londres, em 05 de maio de 1875.

4 Recomendamos a leitura da carta de Friedrich Engels a Karl Kautsky, escrita em Londres, em 23 de fevereiro de 1891. (Excertos). 
Cada passo do movimento real é a mais importante do que uma dúzia de programas. Se, portanto, não podia - e as circunstâncias do momento não o permitiam - ir além do Programa de Eisenach, então era melhor ter firmado um acordo para a ação contra o inimigo comum. Mas, ao se conceber programas de princípios (em vez de postergar isso até que tal programa possa ser preparado por uma longa atividade comum), o que se faz é fornecer ao mundo as balizas que servirão para medir o avanço do movimento do partido. (MARX, 2012, p. 20-21).

No prefácio da primeira publicação da Crítica do Programa de Gotha, escrito por Friedrich Engels, em Londres, datado de 06 de janeiro de 1891, mais uma vez, encontraremos o registro do posicionamento de Marx, colocado por Engels, sobre a proposta do programa de unificação.

O manuscrito aqui publicado - tanto a carta quanto a crítica do projeto de programa - foi enviado a Bracke em 1875, pouco antes do congresso de unificação de Gotha, para que fosse transmitido a Geib, Auer, Bebel e Liekbnecht e, em seguida, reenviado a Marx. Já que o Congresso do Partido em Halle pôs em pauta a discussão do programa de Gotha, pareceu-me que seria um delito se eu continuasse a ocultar do público esse importante documento - talvez o mais importante - referente a essa discussão. (MARX, 2012, p. 17).

Aqui, no prefácio, Engels explica o porquê da atitude de Marx ao utilizar uma linguagem veemente, ou seja, uma linguagem combativa, violenta e de força impetuosa, conforme se verifica na passagem abaixo:

\begin{abstract}
A linguagem veemente com que o manuscrito foi redigido deveu-se a duas circunstâncias. Em primeiro lugar, Marx e eu estávamos envolvidos com o movimento alemão mais intimamente do que com qualquer outro; assim, o retrocesso decisivo anunciado nesse projeto de programa só podia nos perturbar violentamente. Em segundo lugar, naquele momento - apenas dois anos após o Congresso de Haia da Internacional - estávamos na mais acalorada luta contra Bakunin e seus anarquistas, que nos apontavam como os responsáveis por tudo que acontecia no movimento operário na Alemanha; tínhamos razões para esperar que também nos fosse impingida a secreta paternidade desse programa. [...]. (MARX, 2012, p. 18).
\end{abstract}

$\mathrm{Na}$ carta $^{5}$ que enviou a August Bebel (um dos fundadores e líderes da socialdemocracia alemã e da Segunda Internacional), em 18-28 de março de 1875, Friedrich Engels mostra também sua preocupação com o projeto do programa de unificação, além de afirmar sua convicção de que a unificação não duraria nem sequer um ano.

5 Recomendamos a leitura da carta de Friedrich Engels a August Bebel, escrita em Londres, 18-28 de março de 1875 .

\begin{tabular}{|l|l|l|l|l|}
\hline Gevista Qialectus & Ano 10 & n. 23 & Maio - Agosto 2021 & p. $178-193$ \\
\hline
\end{tabular}


Você me pergunta o que achamos da questão da unificação. Infelizmente, estamos na mesma situação que você. Nem Liebknecht nem ninguém nos deu qualquer informação, e assim também não sabemos mais do que o que sai nos jornais, e neles não se diz nada há cerca de oito dias, quando recebemos o projeto de programa. Este nos deixou, certamente, bastante aturdidos. (MARX, 2012, p. 51).

Já na carta enviada a Wilhelm Bracke ${ }^{6}$, em 11 de outubro de 1875, após o congresso de unificação dos partidos, Engels, mais uma vez, ao concordar com Bracke, afirma que "essa unificação traz em si o germe da cisão, e ficarei feliz se, então, apenas os incuráveis fanáticos caírem, mas não todo um grupo de homens corajosos que, se bem instruídos, podem se tornar úteis. ” (MARX, 2012, p. 60-61).

Na mesma carta, Engels apresenta de maneira didática a sua compreensão do programa em sua redação final em três partes:

1. Fraseologias lassallianas e termos que não poderiam ter sido adotados sob nenhuma condição. Se duas frações se unem, não se põe no programa de união aquilo que é controverso. Ao permitir que isso ocorresse, nossos homens se submeteram espontaneamente ao mais degradante jugo. 2. Uma série de reivindicações vulgar-democráticas, concedidas no espírito e no estilo do Partido Popular. 3. Um grande número de frases sobre o dever ser do comunismo, em sua maioria apoiadas no Manifesto, porém tão distorcidas em sua redação que, quando vistas de perto, revelam as mais revoltantes asneiras. Quando não se entende dessas coisas, deve-se desistir de escrever sobre elas ou copiar literalmente daqueles que entendem delas. (MARX, 2012, p. 61).

\section{2-) Considerações sobre a Crítica do Programa de Gotha (1875)}

A Crítica do Programa de Gotha (1875) é um importante documento de caráter histórico e político para pensar a construção de uma sociedade comunista. Escrito de abril ao começo de maio de 1875 por Karl Marx e publicada na Alemanha por Friedrich Engels, em meados de 1891, isto é, 15 anos depois de sua elaboração. Tal documento mantém a sua atualidade, apesar dos passados 129 anos desde a sua primeira publicação.

$\mathrm{Na}$ Crítica do Programa de Gotha (1875), encontraremos o rigoroso posicionamento de Marx em relação ao esboço de programa que fora elaborado durante o Pré-

6 Recomendamos a leitura da carta de Friedrich Engels a Willhelm Bracke, escrita em Londres, em 11 de outubro de 1875 .

\begin{tabular}{|l|l|l|l|l|}
\hline Govista Dialectus & Ano 10 & n. 23 & Maio - Agosto 2021 & p. $178-193$ \\
\hline
\end{tabular}


Congresso de Gotha, realizado em 14 e 15 de fevereiro de 1875, com a finalidade de unificação dos partidos operários alemães, a saber: Associação Geral do Trabalhadores Alemães e Partido Social-Democrata dos Trabalhadores, para formar, assim, o Partido Operário Socialista da Alemanha.

Embora muitos compreendam como uma crítica pontual, a violenta e barulhenta crítica de Marx ao projeto de programa de unificação dos partidos está recheada de provocações políticas, sociais e históricas, além de seu posicionamento seguro em defesa da causa comunista.

Segundo o sociólogo Michael Löwy (2012), ao escrever o prefácio à edição brasileira da Crítica do Programa de Gotha,

Este documento é um dos raros textos de Marx que tratam da sociedade comunista do futuro, da qual ele define em duas etapas distintas: a que leva as marcas de nascença da velha sociedade, estruturada pelo "igual direito" - a cada um segundo seu trabalho - e a fase superior, baseada no generoso princípio que parece resumir em si toda a força utópica do marxismo - "de cada um segundo suas capacidades, a cada um segundo suas necessidades. (MARX, 2012, p. 11).

Alguns pontos tratados no documento, no nosso entendimento, mais uma vez, não perderam sua atualidade com o passar do tempo, pois entendemos que ainda não superamos o modo capitalista de produção, uma forma de organização social que produz e distribui mercadorias em caráter privado. Portanto, nesse sentido, uma sociedade que mantém a exploração do homem pelo próprio homem, que alimenta a desigualdade social, a miséria em todos os sentidos imagináveis (material e intelectual), enfim, uma forma societária constituída social e historicamente para degenerar o próprio homem.

Ao analisarmos os pontos colocados no referido projeto de programa, veremos que o primeiro ponto criticado por Marx, abordado neste texto, no início das Glosas Marginais ao Programa do Partido Operário Alemão trata-se da afirmação de que "o trabalho é fonte de toda a riqueza e toda a cultura". (MARX, 2012, p. 23). Na explicação de Marx:

O trabalho não é a fonte de toda riqueza. A natureza é a fonte dos valores de uso (e é em tais valores que consiste propriamente na riqueza material!), tanto quanto o é o trabalho, que é apenas a exteriorização de uma força natural, da força de trabalho humana." (MARX, 2012, p. 23).

\begin{tabular}{|l|l|l|l|l|}
\hline Qenista Dialectus & Ano 10 & n. 23 & Maio - Agosto 2021 & p. 178 - 193 \\
\hline
\end{tabular}


Para Marx (2012), essa frase pode ser encontrada em todos os manuais infantis e está correta, desde que se subtenda que o trabalho se realiza com os objetos e os meios a ele pertinentes. Mas, comenta Marx, "um programa socialista não pode permitir que tais fraseologias burguesas possam silenciar as condições que, apenas elas, dão algum significado a essas fraseologias.” (MARX, 2012, p. 23).

Aqui, nesse momento, é possível verificar a compreensão de Marx no que toca a importância da natureza no que se refere à produção de riqueza material, uma vez que a natureza é também fonte dos valores de uso, logo, sem considerar a natureza é impossível à realização do trabalho ${ }^{7}$, pois esta garante também os meios necessários para a efetivação deste último.

Nas palavras de Marx (2012), os burgueses possuem muitas razões para atribuir essa "força sobrenatural de criação" ao trabalho, uma vez se apropriando do trabalho (incluindo suas condições para realização), resta ao homem, a título de propriedade, somente sua força de trabalho. Logo, ele (o homem) só poderá trabalhar com a autorização do burguês, só poderá viver com a sua permissão. Em caráter de denúncia, Marx apresenta o antagonismo de classes existente na sociedade capitalista, de um lado, os proprietários dos meios de produção social (a burguesia), e do outro, os trabalhadores que nada possuem, a não ser a sua força de trabalho que deverá ser levada ao mercado para a garantia da sua própria vida (os proletariados, a classe dos operários modernos).

A crítica de Marx no tocante a forma de trabalho desenvolvida e existente na sociedade capitalista e suas consequências para a organização social se mantém com bastante vivacidade na passagem, a saber: "[...] $\mathrm{Na}$ medida em que o trabalho se desenvolve socialmente e se torna, desse modo, fonte de riqueza e cultura, desenvolvem-se a pobreza e o abandono do lado do trabalhador, a riqueza e a cultura do lado do não trabalhador. " (MARX, 2012, p. 25). Tal passagem constitui um dos momentos belíssimos do documento que se mantém com muita vivacidade nos dias atuais, refletindo as contradições reais da sociedade capitalista.

7 No manuscrito, a saber: Sobre o papel do trabalho na transformação do macaco em homem, escrito por Friedrich Engels em 1876, encontra-se, novamente, tal afirmação: "O trabalho é a fonte de riqueza, afirmam os economistas. Assim é, com efeito, ao lado da natureza, encarregada de fornecer os materiais que ele converte em riqueza. O trabalho, porém, é muitíssimo mais do que isso. É a condição básica e fundamental de toda a vida humana. E em tal grau que, até certo ponto, podemos afirmar que o trabalho criou o próprio homem." (ENGELS, 1980, p. 269).

\begin{tabular}{|l|l|l|l|l|}
\hline Q & Ano 10 & n. 23 & Maio - Agosto 2021 & p. 178 - 193 \\
\hline
\end{tabular}


Sem dúvida, Marx não deixaria passar despercebido o "ponto" 03 (três) da primeira parte do esboço do programa que diz: “3) A libertação do trabalho requer a elevação dos meios de trabalho a patrimônio comum da sociedade e a regulação cooperativa [genossenschaftliche] do trabalho total, com distribuição justa do fruto do trabalho.” (MARX, 2012, p. 27).

Depois de uma longa exposição para mostrar as contradições e incoerências contidas na referida afirmação, Marx vai revelando, aos poucos, as teses lassallianas que fundamentam o esboço do programa de princípios do Partido Operário Socialista da Alemanha e, ao mesmo tempo, afirmando seu posicionamento contrário a esse programa de princípios que não tem nada a ver com o comunismo defendido pelos autores do Manifesto Comunista (1848).

A título de exemplo, sobre essas teses, temos a defesa pela distribuição justa do "Fruto integral do trabalho" (MARX, 2012, p.28). Palavra de ordem propagada por Ferdinand Lassalle, que de acordo com Marx é "uma noção vazia no lugar de conceitos econômicos determinados". (MARX, 2012, p.27).

Ainda, no decorrer desses longos comentários, Marx (1875) apresenta a sua preocupação com a sociedade comunista, não como ela se desenvolveu a partir de suas próprias bases, mas, ao contrário, “como ela acaba de sair da sociedade capitalista, portanto trazendo de nascença as marcas econômicas, morais e espirituais herdadas da velha sociedade de cujo ventre ela saiu." (MARX, 2012, p. 29). Na ocasião, Marx aponta duas fases distintas dessa nova forma societária de organização humana: 1) momento inicial, ou seja, de surgimento da sociedade comunista, depois de um longo trabalho de parto, da sociedade capitalista. Neste momento, várias distorções são inevitáveis, a exemplo, o igual direito, que a princípio ainda é o direito burguês. 2) fase superior da sociedade comunista, que se realizará

[...] quando tiver sido eliminada a subordinação escravizadora dos indivíduos à divisão do trabalho e, com ela, a oposição entre trabalho intelectual e manual; quando o trabalho tiver deixado de ser mero meio de vida e tiver se tornado a primeira necessidade vital; quando, juntamente com o desenvolvimento multifacetado dos indivíduos, suas forças produtivas também tiverem crescido e todas as fontes da riqueza coletiva jorrarem em abundância, apenas então o estreito horizonte jurídico burguês poderá ser plenamente superado e a sociedade poderá escrever em sua bandeira: "De cada um segundo suas capacidades, a cada um segundo suas necessidades!”. (MARX, 2012, p. 31-32). 
Por fim, após a belíssima exposição, Marx mostra mais um erro gravíssimo encontrado no esboço do programa, o fato de ter transformado a "distribuição" em algo essencial e ter dado muita atenção para ela. Segundo Marx (2012), o socialismo vulgar ${ }^{8}$ e uma parte da democracia herdaram da economia burguesa a maneira de tratar a distribuição como algo apartado do modo de produção e de expor o socialismo como uma doutrina social que gira em torno da distribuição.

\begin{abstract}
A distribuição dos meios de consumo é, em cada época apenas a consequência da distribuição das próprias condições de produção; contudo, esta última é uma característica do próprio modo de produção. O modo de produção capitalista, por exemplo, baseia-se no fato de que as condições materiais de produção estão dadas aos não trabalhadores sob a forma de propriedade do capital e de propriedade fundiária, enquanto a massa é a proprietária somente da condição pessoal de produção, da força de trabalho. Estando assim distribuídos os elementos da produção, daí decorre por si mesma a atual distribuição dos meios de consumo. Se as condições materiais de produção fossem propriedade coletiva dos próprios trabalhadores, então o resultado seria uma distribuição dos meios de consumo diferente da atual. [...]. (MARX, 2012, p. 32-33).
\end{abstract}

Assim, a crítica de Marx não se trata de uma crítica infundada, movida apenas por uma rivalidade política, pois é notório o retrocesso do novo programa de princípios em comparação ao Programa de Eisenach (1869) que fora criado no momento de fundação do Partido Operário Social-Democrata. Este último apresentava em seus fundamentos uma base marxista de compreensão da realidade material e buscava em suas reivindicações ações concretas de enfrentamento ao Capital (forma de organização social).

Outra tese lassalliana, apontada por Marx, que merece destaque é a tese da "lei de bronze do salário", encontrada na segunda parte do esboço do programa de Gotha.

Partindo desses princípios, o Partido Operário Alemão ambiciona, por todos os meios legais, alcançar o Estado livre - e - a sociedade socialista, a superação do sistema salarial juntamente com a lei de bronze do salário - e - da exploração em todas as suas formas, a eliminação de toda desigualdade social e política. (MARX, 2012, p. 37).

8 Segundo N.T com (*), localizada na página 33 da edição brasileira da Crítica do Programa de Gotha, publicada pela Boitempo editorial, Marx e Engels chamavam de socialismo vulgar o socialismo eclético, que "Engels, por exemplo, identificava no socialismo francês daqueles anos e que se concentrava sobretudo na exigência de uma distribuição "mais justa" dos produtos do trabalho, sem considerar suficientemente o nexo essencial entre a distribuição e as relações de produção, elemento central da teoria marxiana." (MARX, 2012, p.33).

\begin{tabular}{|c|c|c|c|c|}
\hline Q Rovista Dialectus & Ano 10 & n. 23 & Maio - Agosto 2021 & p. $178-193$ \\
\hline
\end{tabular}


Sem demorar muito para chegar ao assunto, Marx ironiza "Superando-se o trabalho assalariado, é claro que se superam também suas leis, sejam elas "de bronze" ou de esponja". (MARX, 2012, p. 37). Na ocasião, afirma ainda que da "lei de bronze do salário", a única coisa de Lassalle é o termo "de bronze" tomada de empréstimo das "grandes, eternas, brônzeas leis" de Goethe. (MARX, 2012, p. 38).

Sem perder a oportunidade, Marx aproveita o ensejo para revelar o que existe por trás da "lei de bronze dos salários", isto é, seu fundamento. Comenta, então, Marx: "Mas se aceito a lei com o carimbo de Lassalle e, portanto, tal como ele a compreende, então tenho de aceitar também seu fundamento.” (MARX, 2012, p.38). Pergunta, assim, Marx: E qual é ele? (MARX, 2012, p. 38). Como resposta, diz o pensador materialista que conforme Lange mostrou logo após a morte de Lassalle, o fundamento desta tese lassalliana é a teoria malthusiana da população ${ }^{9}$.

Comenta, ainda, Marx:

[...] Mas, estando certa essa teoria, então mesmo que eu supere sem vezes o trabalho assalariado, ainda assim não podei superar a lei, pois esta rege não apenas o sistema do trabalho assalariado, mas todo sistema social. Baseado justamente nisso, os economistas vêm demonstrando, há cinquenta anos ou mais, que o socialismo não pode acabar com a miséria, que é fundada na natureza, mas apenas generalizá-la, repartindo-a igualmente por toda a superfície da sociedade! (MARX, 2012, p.38).

Ao revelar o fundamento da "lei de bronze do salário", Marx entende que a oposição de Lassalle ao trabalho assalariado gira quase que exclusivamente em torna dessa suposta lei. Diante desta referida compreensão, percebemos que a "lei de bronze do salário" é uma tese absurda que nas palavras de Engels se trata de uma das fraseologias lassallianas.

Para Marx (2012), isso não é a questão principal. Ainda que se considere por completo a falsa concepção lassalliana acerca da lei, o retrocesso revoltante consiste na seguinte passagem abaixo:

Desde a morte de Lassalle, impôs-se em nosso partido o ponto de vista científico de que salário não é o que aparenta ser, isto é, o valor do trabalho ou seu preço, mas

9 Na carta escrita por Friedrich Engels a August Bebel, em 18-28 de março de 1875, Engels afirma que a "lei de bronze" lassalliana repousa sobre uma visão econômica totalmente ultrapassada, ou seja, a de que o trabalhador recebe em média apenas o mínimo do salário, e precisamente porque, segundo a teoria da população de Mathus, há trabalhadores demais. (MARX, 2012, p.54). 
apenas uma forma disfarçada do valor ou preço da força de trabalho. Com isso, foi descartada toda a concepção burguesa do salário até hoje, assim como toda a crítica a ela dirigida, e ficou claro que o trabalhador assalariado só tem permissão de trabalhar para sua própria vida, isto é, para viver, desde que trabalhe de graça um determinado tempo para o capitalista (por isso, também para aqueles que, juntamente com ele, consomem a mais-valia); que o sistema inteiro da produção capitalista gira em torno do aumento desse trabalho gratuito graças ao prolongamento da jornada de trabalho ou do crescimento da produtividade, uma maior pressão sobre a força de trabalho etc.; que, por conseguinte, o sistema do trabalho assalariado é um sistema de escravidão e, mais precisamente, de uma escravidão que se torna tanto mais cruel na medida em que as forças produtivas sociais do trabalho se desenvolvem, sendo indiferente se o trabalhador recebe um pagamento maior ou menor. E depois que esse ponto de vista se estabeleceu cada vez mais em nosso partido, retrocede-se agora aos dogmas de Lassalle, mesmo que hoje seja impossível ignorar que Lassalle não sabia o que era o salário, senão que, seguindo os economistas burgueses, tomava a aparência da coisa por sua essência. (MARX, 2012, p. 39).

Nas palavras de Marx, esse retrocesso pode ser entendido da seguinte maneira:

É como se, entre escravos que tivessem desvendado o segredo da escravidão e iniciado uma rebelião, um escravo preso às concepções ultrapassadas escrevesse no programa da rebelião: “A escravidão tem de ser abolida, pois o custo de manutenção dos escravos não pode, no sistema de escravidão, ultrapassar certo limite máximo, bastante baixo!" (MARX, 2012, p. 39).

Já na terceira parte da crítica do esboço do programa de Gotha, Marx ironiza, mais uma vez, e não economiza palavras ao apresentar seu posicionamento no que refere ao seguinte ponto:

O Partido Operário Alemão exige, para conduzir à solução da questão social, a criação de cooperativas de produção com subvenção estatal e sob o comando democrático do povo trabalhador. Na indústria e na agricultura, as cooperativas de produção devem ser criadas em proporções tais que delas surjam a organização socialista do trabalho total. (MARX, 2012, p. 39-40).

Segundo Marx, "depois da "lei de bronze do salário" de Lassalle, temos agora a panaceia do profeta!" (MARX, 2012, p.40). Que é "conduzida” de forma digna! Pois, tal passagem ignora a luta de classes existente. A organização social dos trabalhadores, em vez de surgir do processo revolucionário, surge da "subvenção estatal", ou seja, do auxílio dado pelo Estado para o desenvolvimento das cooperativas de produção que deveriam ser criadas pelos trabalhadores sem interferência do Estado e da burguesia. Ainda, de acordo, com Marx,

\begin{tabular}{|l|l|l|l|l|}
\hline Gevista Qialectus & Ano 10 & n. 23 & Maio - Agosto 2021 & p. $178-193$ \\
\hline
\end{tabular}


“É algo digno da presunção de Lassalle imaginar que, por meio de subvenção estatal, seja possível construir uma nova sociedade da mesma forma que se constrói uma nova ferrovia!”. (MARX, 2012, p.40).

Continuando sua exposição sobre este ponto, Marx (2012) assevera que, em primeiro lugar, no contexto da época, meados do século XIX, o "povo trabalhador" na Alemanha consistia majoritariamente de camponeses, e não em trabalhadores assalariados oriundos da grande indústria. Em segundo lugar, "democrático", no seu entendimento, traduzido para o alemão, significa "sob o governo do povo". E, logo em seguida apresenta a pergunta, "Mas o que quer dizer o "controle sob o governo do povo do povo trabalhador?" (MARX, 2012, p. 40). E, na sequência, conclui: “[...] E ainda mais quando se trata de um povo trabalhador que, ao apresentar essas exigências ao Estado, expressa sua plena consciência de que não só não está no poder, como não está maduro para ele!” (MARX, 2012, p. 40).

Após o desenvolvimento da 1) Contextualização da Crítica do Programa de Gotha (1875) no debate da época e 2) Considerações sobre a Crítica do Programa de Gotha (1875), Chegamos, assim, ao ponto específico que tratará sobre a temática da educação abordada por Marx na Crítica do Programa de Gotha (1875). Por ser um dos momentos de grande relevância para esta pesquisa, não desmerecendo o conjunto da obra, abordar-se-á o assunto na terceira parte deste artigo.

\section{3-) A temática da educação (formal) abordada por Marx na Crítica do Programa de Gotha (1875)}

No que se refere à educação formal, encontraremos na Crítica do Programa de Gotha (1875) pouquíssimas passagens que abordam sobre essa temática, principalmente, por se tratar de um documento político de enfrentamento ao Capital. Porém, é notório verificar que a educação não passou despercebida por Marx no momento de construção de sua crítica aos pontos colocados na proposta de unificação dos partidos operários alemães. Assim, é importante destacar a seguinte passagem, localizada na parte IV (quatro) da Crítica do Programa de Gotha (1875), exatamente no "ponto” B, do referido projeto de programa: "B) “O Partido Operário Alemão exige, como base espiritual e moral do Estado: 1) Educação popular universal e igual sob incumbência do Estado. Escolarização universal obrigatória. Instrução gratuita.” (MARX, 2012, p. 45). Na sequência, Marx, no mesmo documento, 
apresenta sua crítica também a esse ponto específico que trata sobre a exigência de uma educação popular e igual sob a incumbência do Estado.

\begin{abstract}
Educação popular igual? O que se entende por essas palavras? Crê-se que na sociedade atual (e apenas ela está em questão aqui) a educação possa ser igual para todas as classes? Ou se exige que as classes altas também devam ser forçadamente reduzidas à módica educação da escola pública, a única compatível com as condições econômicas não só do trabalhador assalariado, mas também do camponês? (MARX, 2012, p. 45).
\end{abstract}

Com exatamente 57 anos de idade, este filósofo, depois de um longo processo de maturidade intelectual, após a ruptura da filosofia defendida pelos jovens hegelianos de esquerda e calejado por uma vasta experiência política, chama atenção para o que se pede e, no ensejo, pergunta se é possível crê que, na sociedade atual, a educação possa ser igual para todas as classes. A sociedade atual, nesse contexto abordado no documento, trata-se da sociedade capitalista, que em meados do século XIX continuava se consolidando na Europa e avançava, cada vez mais, para os demais continentes.

Na referida passagem, sobre a educação, observamos a contribuição de Marx no sentido de perceber uma impotência nesse pedido, pois Marx visualiza o problema na estrutura da organização social. É importante lembrar que no Manifesto Comunista (1844), Marx apresenta o processo histórico e social de formação da sociedade capitalista, uma forma de organização social dividida em classes antagônicas, de tal forma que, de um lado, encontram-se os donos dos meios de produção e compradores da força de trabalho humana e, do outro lado, encontram-se os proletários, os donos, somente, da sua própria força de trabalho que deverá ser vendida no mercado para garantia de sua sobrevivência. Ao se apropriarem da força de trabalho humana, uma vez que já possuem a matéria e os meios para a produção de mercadorias, os burgueses acumulam riquezas ("uma grande coleção de mercadorias"), produzem cultura, porém, por se tratar de um modo privado de produção de mercadorias, sua distribuição de riqueza ocorrerá também de modo privado, isto é, ao trabalhador só é dado o indispensável para sua sobrevivência como trabalhador, alimentando assim a estrutura do modo de produção capitalista que, por sua vez, garantirá à perpetuação das desigualdades sociais.

Portanto, ao solicitar e exigir uma educação popular igual para todos sob incumbência do Estado burguês sem modificar a estrutura da organização dessa forma de 
Estado e do modo de produção social, o pedido ("ponto" norteador do Partido Operário Alemão), um dos "pontos” do programa, está também "totalmente infestado da credulidade servil do Estado que caracteriza a seita lassalliana". (MARX, 2012, p. 46). Podemos verificar que este pedido, como bem observa Marx, não ultrapassa os limites estruturais do capital ${ }^{10}$.

Ao retornar para o texto, Crítica do Programa de Gotha (1875), Marx continua sua crítica sobre a temática da educação abordada no documento que, como se ver, não se trata de uma crítica pontual.

Como um bom historiador que fora, Marx procurou acompanhar de perto o desenvolvimento da história da civilização humana. Afirma no documento em questão que:

\begin{abstract}
"Escolarização universal e obrigatória. Instrução gratuita". A primeira existe na Alemanha, a segunda na Suíça [e] nos Estados Unidos, para as escolas públicas. Que em alguns estados deste último também sejam "gratuitas" as instituições de ensino "superior" significam apenas, na verdade, que nesses lugares os custos da educação das classes altas são cobertos pelo fundo geral dos impostos. O mesmo vale, diga-se de passagem, para a "assistência jurídica gratuita" exigida no artigo 5. A justiça criminal é gratuita em toda parte; a justiça civil gira quase exclusivamente em torno de conflitos de propriedade, dizendo respeito, portanto, quase exclusivamente às classes proprietárias. Elas devem mover seus processos à custa do tesouro público? (MARX, 2012, p. 45-46).
\end{abstract}

Segundo Marx, "O parágrafo sobre as escolas devia ao menos ter exigido escolas técnicas (teóricas e práticas) combinadas com a escola pública”. (MARX, 2012, p. 46). Uma tese $^{11}$ de grande importância, pois, aqui, verifica-se que não se trata de uma defesa em nome

10 No debate atual sobre a educação, um dos filósofos leitores de Marx e que, diga-se de passagem, pensa com Marx, István Mészáros, na Obra A Educação Para Além do Capital, publicada também pela Editorial Boitempo, afirmará que “[...] As mudanças sob tais limitações, apriorísticas e prejulgadas, são admissíveis apenas com o único e legítimo objetivo de corrigir algum detalhe defeituoso da ordem estabelecida, de forma que sejam mantidas intactas as determinações estruturais fundamentais da sociedade como um todo, em conformidade com as exigências inalteráveis da lógica global de um determinado sistema de reprodução. [...]." (MÉSZÁROS, 2008, p. 25).

11 Na segunda parte da obra, Educação, saber, produção em Marx e Engels de autoria de Maria Alice Nogueira (1993), o sentido da união (ensino e produção), no entendimento de Marx e Engels, de acordo com a pesquisadora, deveria contribuir para a derrubada das condições capitalistas de exploração. No entendimento de Maria Alice Nogueira (1993), duas ordens de razões levam a essa compreensão: 1) A concretização do princípio da "união" deveria, no entender deles [Marx e Engels], contribuir para a derrubada das condições capitalistas de exploração. Assim sendo, fica claro que o alcance desse princípio transcende os limites das formas produtivas submetidas à lógica do capital; 2) Ao se fazer o levantamento de todas as passagens onde a ideia de união do ensino com a produção é evocada, pôde-se perceber que, embora a expressão "trabalho produtivo" seja a mais frequente, ela é substituída, em certos textos, por expressões tais como: "trabalho físico", "trabalho manual", "trabalho fabril" ou ainda "produção material", apontando todas elas para o sentido geral da noção de trabalho.

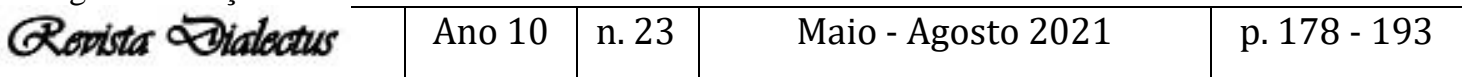


do Capital, mas uma defesa no sentido de melhorar a condição da classe trabalhadora para alcançar uma sociedade mais humana. Esta defesa não deve ser analisada sem a compreensão da obra (Crítica do Programa de Gotha) em sua totalidade, pois seria uma contradição diante das críticas virulentas de Marx ao socialismo fundamentado nas teses lassallianas a defesa de tal afirmação em benefício do Capital.

Conhecedor da precária educação oferecida nas escolas públicas e da impossibilidade da existência de uma educação popular igual para todas as classes na sociedade capitalista, Marx, pensando no presente sem perder de vista o futuro da classe trabalhadora parte na defesa de uma escola técnica (teórica e prática) combinada com a educação pública e condena: 1) uma educação popular sob a incumbência do Estado; 2) a influência do governo e da igreja sobre as escolas públicas.

Pois, segundo Marx,

[...] Uma coisa é estabelecer, por uma lei geral, os recursos das escolas, a qualificação do pessoal docente, os currículos etc. e, como ocorre nos Estados Unidos, controlar a execução dessas prescrições legais por meio de inspetores estatais, outra muito diferente é conferir ao Estado o papel de educador do povo! [...]. (MARX, 2012, p. 45-46).

Percebe-se, com bastante facilidade, o posicionamento contrário de Marx em relação às teses socialistas de Ferdinand Lassalle que tinha o Estado como facilitador dos grandes progressos da civilização humana.

Ainda, no mesmo documento, ao exigir a proibição do trabalho infantil, parte IV (quatro), "ponto" B, "tópico" 3) "Limitação do trabalho das mulheres e proibição do trabalho infantil.”, como resposta, Marx assevera que “A proibição geral do trabalho infantil é incompatível com a existência da grande indústria e, por essa razão, um desejo vazio e piedoso." (MARX, 2012, p. 47).

E justifica,

A aplicação dessa proibição - se fosse possível - seria reacionária, uma vez que, com uma rígida regulamentação da jornada de trabalho segundo as diferentes faixas etárias e as demais medidas preventivas para a proteção das crianças, a combinação de trabalho produtivo com instrução, desde tenra idade, é um dos mais poderosos meios de transformação da sociedade atual. (MARX, 2012, p. 47-48).

\begin{tabular}{|l|l|l|l|l|}
\hline Govista Dialectus & Ano 10 & n. 23 & Maio - Agosto 2021 & p. $178-193$ \\
\hline
\end{tabular}


Entende-se que, nesse contexto, por mais que possa parecer algo desumano, seria de fato um retrocesso à abolição geral do trabalho infantil, pois com a existência de leis que garantissem e regulassem o trabalho infantil, nas diferentes faixas etárias, com medidas preventivas para a proteção de crianças, esse pedido apresenta-se, de fato, como um retrocesso, sendo incompatível com a existência e avanço da grande indústria. Assim, ao defender a união de trabalho produtivo com instrução, desde tenra idade, Marx (2012) acredita que a efetivação dessa tese, no campo das ações concretas (materiais), torna-se um dos mais poderosos meios de transformação da sociedade capitalista, no nosso entendimento, capaz também de contribuir para a construção de uma sociedade mais humana, solidária e estruturada em novas relações sociais, tendo como centro de referência o próprio homem.

\section{Referências}

BRANDÃO, Carlos Rodrigues. O que é educação. São Paulo: Brasiliense. $28^{a}$ edição, 1993.

ENGELS, Friedrich. Sobre o papel do trabalho na transformação do macaco em homem. In: KARL, Marx; ENGELS, Friedrich. Obras escolhidas. São Paulo: Alfa-Omega, 2v, 1980.

MANACORDA, Mario Alighiero. Marx e a pedagogia moderna. [tradução Newton Ramosde-Oliveira]. Campinas, SP: Editora Alínea, 2007.

MARX, Karl \& ENGELS, Friedrich. Textos sobre educação e ensino. São Paulo, Editora Moraes, 1992.

. Manifesto comunista. Organização e introdução de Osvaldo Coggiola. São Paulo. Editorial Boitempo. 2005.

MARX, Karl. Crítica do programa de Gotha. Seleção, tradução e notas de Rubens Enderle - São Paulo: Boitempo, 2012.

O capital: Crítica da Economia Política: Livro I. O processo de produção do capital. Tradução de Rubens Enderle - São Paulo: Boitempo editorial, 2011.

MÉSZÁROS, Istvan. A educação para além do capital. [tradução Isa Tavares]. - 2. Ed.São Paulo: Boitempo, 2008.

NOGUEIRA, Maria Alice. Educação, saber, produção em Marx e Engels. $2^{a}$ ed. - São Paulo: Cortez, 1993.

SUCHODOLSKI, Bogdan. Teoria marxista da educação. Tradução de Maria Carlota Melo. Editorial Estampa, Lisboa, 1976. 
